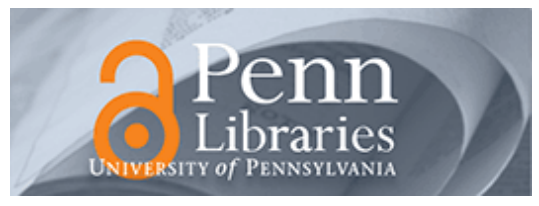

University of Pennsylvania

ScholarlyCommons

$1-1-2002$

\title{
Subject-Matter Content: How does it Assist the Interactional and Linguistic Needs of Classroom Language Learners?
}

Teresa Pica

University of Pennsylvania, teresap@gse.upenn.edu

Follow this and additional works at: https://repository.upenn.edu/gse_pubs

Part of the Curriculum and Instruction Commons

\section{Recommended Citation}

Pica, T. (2002). Subject-Matter Content: How does it Assist the Interactional and Linguistic Needs of Classroom Language Learners?. Retrieved from https://repository.upenn.edu/gse_pubs/40

Postprint version. Published in Modern Language Journal, Volume 86, Issue 1, 2002, pages 1-19.

Publisher URL: http://hdl.library.upenn.edu/1017/5212

This paper is posted at ScholarlyCommons. https://repository.upenn.edu/gse_pubs/40

For more information, please contact repository@pobox.upenn.edu. 


\title{
Subject-Matter Content: How does it Assist the Interactional and Linguistic Needs of Classroom Language Learners?
}

\author{
Abstract \\ This study focused on the role of subject-matter content in second language (L2) learning. It sought to \\ identify ways in which teachers modified classroom interaction about subject-matter content in order to \\ assist the input, feedback, and production needs of L2 learners, and to promote their attention to \\ developmentally difficult relationships of $L 2$ form and meaning that they had not fully acquired. Data were \\ collected from 6 preacademic English L2 classes, whose content consisted of thematic units on film and \\ literature. Each class was composed of 10-15 high intermediate English L2 students and their teachers. \\ Analysis of the data focused on teacher-led discussions, because these were the predominant mode of \\ interaction in each of the classes, and on form-meaning relationships encoded in noun and verb forms for \\ purposes such as reference, retelling, argument, and speculation regarding film and literary content. \\ Results of the study revealed numerous contexts in which the discussion interaction might have been \\ modified for the kinds of input, feedback, or production that could draw students' attention to \\ developmentally difficult form-meaning relationships. However, there were relatively few instances in \\ which this actually occurred. Instead, the teachers and students tended to exchange multiutterance texts, \\ the comprehensibility of which provided little basis for modified interaction and attention to form and \\ meaning.

\section{Disciplines} \\ Curriculum and Instruction
}

\section{Comments}

Postprint version. Published in Modern Language Journal, Volume 86, Issue 1, 2002, pages 1-19.

Publisher URL: http://hdl.library.upenn.edu/1017/5212 
Subject-Matter Content: How does it Assist

the Interactional and Linguistic Needs of Classroom Language Learners?

TERESA PICA

University of Pennsylvania

3700 Walnut St.

Philadelphia, PA 19104-6216

teresap@gse.upenn.edu 


\begin{abstract}
This study focused on the role of subject-matter content in second language (L2) learning. It sought to identify ways in which teachers modified classroom interaction about subject-matter content in order to assist the input, feedback, and production needs of L2 learners, and to promote their attention to developmentally difficult relationships of L2 form and meaning that they had not fully acquired. Data were collected from 6 preacademic English L2 classes, whose content consisted of thematic units on film and literature. Each class was composed of 10-15 high intermediate English L2 students and their teachers. Analysis of the data focused on teacher-led discussions, because these were the predominant mode of interaction in each of the classes, and on form-meaning relationships encoded in noun and verb forms for purposes such as reference, retelling, argument, and speculation regarding film and literary content. Results of the study revealed numerous contexts in which the discussion interaction might have been modified for the kinds of input, feedback, or production that could draw students' attention to developmentally difficult form-meaning relationships. However, there were relatively few instances in which this actually occurred. Instead, the teachers and students tended to exchange multiutterance texts, the comprehensibility of which provided little basis for modified interaction and attention to form and meaning.
\end{abstract}


More than 15 years have passed since Merrill Swain drew from her massive data base on French immersion students to express concerns about their comprehension strengths and production shortcomings, and to point out discrepancies between their solid achievements in subject-matter content and their uneven mastery of second language (L2) structures. The factors and reasons for these findings were addressed by Swain herself at the time, (Swain, 1985), and have continued to interest second language acquisition (SLA) researchers and professionals ever since.

What might have brought about this outcome, Swain’s data suggested, was an imbalance in opportunities for students to receive L2 input and produce modified output. In effect, immersion classroom interaction had served as an excellent source of meaningful, comprehensible input for the students to learn subject-matter content and to improve their ability to understand spoken and written L2. However, Swain's data also indicated that this input was considerably greater in quantity than the amount of output the students were asked to produce. Their low level of output was of concern, Swain argued, because production of modified, comprehensible output might have been what they needed to broaden the scope and accuracy of their L2 learning. In subsequent research (Swain, 1988, 1991, 1995, 1996), Swain noted another concern about classroom input. Her analysis revealed that the input adjustments teachers made to help students 
understand subject-matter content were limited in scope, salience, complexity, and functionality of L2 morphosyntax, also considered crucial for interlanguage development. In spite of these shortcomings, however, immersion and other classroom approaches oriented toward integration of subject-matter content and L2 learning have continued to thrive in number and variety. These include what are known popularly as sheltered, adjunct, theme-based, and language for specific purposes (LSP) approaches, as well as less explicitly labeled varieties characterized by spoken or written activities conjoined with students' reading of texts, viewing of video or film, and experiences in the community (Mohan, 1979; Brinton, 2000; Carson, Taylor, \& Fredella 1997; Stoller \& Grabe, 1997; Zuengler \& Brinton, 1997). Across academic and professional arenas, these and other incarnations of content-based L2 approaches aim to support students in learning the L2 they need for current, concurrent, or future success at school, in the workplace, and across broader social contexts. As they attempt to address these aims, instructional approaches that integrate L2 and subject-matter content have grounded evaluation of their accomplishments in measures of global proficiency and skill application. These practices raise additional concerns.

\section{EVALUATION OF L2 LEARNING AND CONTENT LEARNING}

Concerns about L2-content integration in the areas of student assessment and program evaluation pertain to options for setting L2 learning criteria and for selecting comparison learners and controls. Although it is possible to base criteria on the acquisition of linguistic forms and structures, sociolinguistic units, or features of text and discourse, it has been more typical to base them on global dimensions of L2 proficiency or on skills for reading, writing, listening, and speaking. Surveys by Pica (1997) and Pica, Washburn, Evans, and Jo (1998) have identified this pattern across a range of approaches 
to L2-content integration, including immersion (Genesee, Polich, \& Stanley, 1977; Hart \& Lapkin, 1989; Ho, 1982; Sternfeld, 1988; Swain, 1991; \& Wesche, 1992); sheltered (Freeman, Freeman, \& Gonzalez, 1987; Hauptman, Wesche, \& Ready, 1988; Lafayette \& Buscaglia, 1985; Sternfeld 1989; and Wesche, 1985); adjunct (Brinton, Snow, \& Wesche, 1989; Snow \& Brinton, 1988); theme-based (Giauque, 1987; Leaver \& Stryker, 1989); and LSP (Graham \& Beardsley, 1986; Hudson, 1991; Peck, 1987).

In their relation to academic skills and overall proficiency, these views of L2 learning are appropriate to many of the instructional goals of L2 and content integration and to the ways in which L2 learning must be evaluated for purposes of pedagogy and policy. Of concern, however, is that, as they overlook the learning of L2 forms and structures that encode subject-matter content, these views have the capacity to hold L2 learners to criteria that meet grade level standards for reading and writing, but disadvantage them in more competitive domains of oral communication with native speakers (NSs).

Yet another concern with assessment and evaluation relates to the groups with whom students' learning of L2 and content are compared. As was illustrated in Pica (1997) and Pica et al. (1998), control and comparison groups used as a basis for evaluating students’ L2 learning have tended to come from foreign language (FL) classrooms. Those groups used as a basis for evaluating content learning have been NSs who share the same L1 as the L2-content students, but who are enrolled in mainstream classes in the L1. As Swain has noted with respect to immersion programs in Canada, the emphasis on NS comparisons in the evaluation of content outcomes reflects the value and emphasis given to content mastery among parents, institutional administrators, and policy makers. (Swain, 1995). This emphasis in evaluation is evident in Genesee et al. (1977), 
Hauptman et al. (1988), Ho (1982), Sternfeld (1988), and Swain (1991). It should be noted, however, that there is only a small sample of studies on which to draw in this area because much of the immersion research was designed to answer theoretical questions or address policy issues regarding L2 development and has not examined students' content learning (Swain, 1991; Swain \& Carroll, 1987; Swain \& Lapkin, 1989; Wesche, 1985, 1992).

The learning of the L2, although recognized as an important goal of content-based instruction, has seldom been subjected to NS level criteria. Instead, the performance of L2 learners in regular FL classrooms has been used in this regard (Hart \& Lapkin, 1989; Hauptman, Wesche, \& Ready, 1988; Ho, 1982; Sternfeld, 1989). This comparison is somewhat imbalanced, however, because FL program students might differ considerably from their content-based counterparts in terms of motivations, home environments and resources, and time spent on language study both in and out of class. As a result, the wider context of language study might be as accountable for students' L2 learning as the actual content-based or FL curricula to which they are exposed.

Several studies have actually looked at NS and FL learner populations as comparison groups (Genesee, Polich, \& Stanley, 1977; Sternfeld, 1988), whereas others have structured their comparison between content classroom L2 learners and NSs (Spilka, 1976; Wesche, 1985, 1992). These studies have revealed significantly higher achievement among the NSs. Among those studies that Harley (1993) reviews is one designed and implemented by Harley herself (Harley 1989), in which she found that French immersion students, after many years of content-L2 instruction, still differed from NSs of French in their expression of imparfait and passé composé. These learners 
continued to exhibit English L1 transfer in their production of these verbs, especially in complex or socially distinctive discourse environments.

There is considerable confidence in the use of subject matter content as an aid to L2 learning and a range of classroom approaches that integrate content and language have emerged in response to learners' needs and interests. There is also a good deal of evidence from assessment and evaluation studies that content-based approaches promote L2 proficiency and facilitate skill learning in ways that are relevant and important to the academic and professional goals of L2 learners. A remaining concern for SLA research, however, is that classroom experiences with subject matter content might not provide sufficient access to the kinds of input, feedback, and production of output that learners need to assist their learning beyond the areas of global L2 proficiency and skill application. These kinds of input, feedback, and production, which are described in the following section, were the basis for the research questions of the present study.

\section{INPUT, FEEDBACK, AND PRODUCTION NEEDS OF L2 LEARNERS}

The theoretical, and in many cases, empirically documented, needs of L2 learners have been described and discussed in syntheses of Ellis (1994), Gass and Selinker (1994), Lightbown and Spada (1993), Long (1996), Pica (1994), and Swain (1995), among others. What this work has revealed is that learners need to access L2 input that is modified for comprehensibility, illustrative of relationships among L2 form, meaning, and function, and responsive to differences between their interlanguage and their L2 target. In addition, learners need to make their output comprehensible, often drawing on emergent morphosyntax to do so.

One of the most comprehensive discussions of input needs appears in Long (1996). According to Long, learners need access to input that provides positive evidence 
or data on L2 form as it encodes message meaning. Sources of positive evidence include spoken and written texts that are in their authentic state, as well as those that have been modified for comprehensibility through simplification, redundancy, and elaboration of their linguistic features, interlocutor expectations, or communicative goals.

As Long argues, such input is an excellent source of data about L2 form and meaning, but it is also an insufficient source of evidence when learners need to master L2 forms that are developmentally difficult because they are too complex, highly redundant, or have little or no perceptual saliency for the complete scope of their functional roles to be noticed. These linguistic elements often occur in reduced syllables, as bound, grammatical morphemes that distinguish complex relationships of verb tense and aspect or sentence modality. Also difficult for learners to access are noun phrase articles, determiners, or gender markings that carry low semantic weight as they encode message meaning.

When learners have difficulty in noticing these forms, there is a tendency for them to develop incomplete or incorrect representations in their interlanguage development, and thereby substitute incorrect versions for correct ones, or omit them altogether. As Long explains, this tendency reveals why learners are believed to need additional, negative evidence about what is not in the L2. Such evidence can be accessed in a variety of ways, including formal instruction on L2 rules, explicit correction of specific features, and implicit feedback from requests for message clarification and confirmation and from interlocutor responses that paraphrase or recast their erroneous utterances.

In addition to the positive and negative evidence that comes from modified input, feedback, and formal instruction, Swain argues that learners’ own production can provide a basis for their learning of L2 form to encode message meaning (). When learners are 
asked to modify their message production toward greater comprehensibility or accuracy, they have an opportunity to move from their rudimentary interlanguage grammar, with its communicative tendency toward semantic processing and juxtaposition of constituent features, to more advanced, syntactic processing and message organization. How learners accomplish this task is not fully understood. However, as Swain puts forth, the need to aim toward message clarity and to repeat and reorganize original messages often pushes learners to modify syntactically what was originally a meaningful message, but whose form was wanting in scope, complexity, and target-like standards of acceptability (Swain, 1985, 1995, 1996; Linnell, 1995).

Empirical studies have shown that many L2 needs can be addressed during the course of informal conversation, open-ended communication, and the exchange of message meaning. Experientially oriented classrooms often make this assumption when they engage learners in role plays, opinion exchanges, and other types of communicative activities (Pica and Doughty, 1985a, b). However, these kinds of meaning-based interactions can lend themselves to an even flow of communication, with little need for learners to focus on form-meaning relationships in input, or to move beyond their current level of L2 development during production of modified L2 output. As a result, their attention needs to be focused only on message meaning. Learners engaged in interaction with meaningful, subject-matter content must therefore be challenged to attend to the form in which meaning is encoded and to notice more developmentally advanced and difficult relationships of form and meaning. As will be discussed below, interactions that involve negotiation of meaning and form-focused intervention and instruction can help them meet such challenges. 


\section{INTERACTIONS THAT ADDRESS INPUT, FEEDBACK, AND PRODUCTION}

\section{NEEDS OF L2 LEARNERS}

Negotiation of Meaning

Negotiation of meaning occurs during communicative interaction, when one interlocutor's message appears to another interlocutor to be unclear, incomprehensible, or incomplete in its meaning. This serves as a trigger for which the other interlocutor utters a signal. The other interlocutor is then expected to respond. The signals and responses of negotiation are often modified linguistically through repetition, reduction, or addition to trigger utterances (Pica, 1992). Modifications of signals and responses also include extraction or segmentation of words, phrases, and clauses from previous utterances, and lexical adjustments through use of paraphrase, synonyms, and descriptors. Signals and responses can be encoded through simple utterances as well, including open signals of “what” or "please repeat," and brief responses of “yes” or “no” (Pica, Holliday, Lewis, \& Morgenthaler 1989; Pica, Holliday, Lewis, Berducci, \& Newman 1991). These modifications promote message comprehensibility as well as the saliency of formmeaning relationships in the message. Example 1, below, and Examples 2-4 to follow, have been composed from patterns in the data of these three earlier studies (Pica, 1992;

Pica et al., 1989; Pica et al., 1991). These examples illustrate the kinds of modifications and interactional features that were identified in these studies.

Example 1:

English L2 Learner

the boys arrive at station

(Trigger)

they arrive at station

\section{NS English}

What did you say about the boys?

(Negotiation Signal)

oh, really 
(Response)

(Topic Continuation)

Here, the NS uttered a signal that indicated difficulty in understanding the learner's message meaning, and also modified the learner's message through segmentation of the phrase the boys and its incorporation into the prepositional phrase about the boys. In so doing, the NS demonstrated to that learner that the boys could appear as both the subject of the learner's statement and object of the NS's preposition. The NS signal thus provided negative evidence on the incomprehensibility of the learner's message meaning, and positive evidence about the form of its noun phrase grammar. The learner responded with modified production of the original trigger, through substitution of the pronoun they. This modification was made to the target-like portion of the trigger but not to the verb arrive, which was the constituent that required greater morphosyntactic accuracy.

The linguistic modifications that occurred in this exchange illustrate how negotiation can provide positive L2 evidence, negative evidence, and modified learner output on relationships of form and meaning. These adjustments also illustrate the inexactness of negotiation in targeting learners' L2 needs. Here, the NS signal alerted the learner to deficiencies in message comprehensibility, but not to the lack of clarity in any specific relationship of form and meaning. As numerous studies have shown, modification of form is abundant within negotiation (Long, 1996, Pica 1994). However, it is often embedded within segmentation and movement of phrase and sentence constituents rather than targeted toward specific encodings in learner output. Some researchers have taken the position that large amounts of negotiation are sociolinguistically inappropriate to L2 learners (Aston, 1986), or are in themselves not a guarantee of L2 learning (Foster, 1998). However, neither of these positions captures the 
fundamental concern of researchers who have carried out studies of the negotiation construct. Rather, it is the inexactness of negotiation, when drawing learners' attention to form and meaning, that limits its sufficiency as a condition for L2 learning. Researchers in the field have continued to emphasize this point (Long 1985, 1996; Pica 1994; Sato 1986).

\section{Form-Focused Intervention}

Form-focused intervention occurs when conversational interaction becomes modified to achieve message comprehensibility, and does so in ways that draw the learner's attention to relationships of L2 form and meaning, through a focus on form (Long \& Robinson, 1998; Doughty \& Williams, 1998). Focus on form, as defined by Long \& Robinson (1998), is viewed as "an occasional shift in attention to linguistic code features - ... triggered by perceived problems with comprehension or production” (p. 23). Other researchers have used the term in ways that emphasize its attentional component. A focus on form need not be triggered by communication problems, but might anticipate them through learner directed models (Doughty \& Williams 1998).

Form-focused intervention can occur within negotiation, as the need to repair conversational breakdowns brings interlocutors to shift attention from a sole emphasis on the exchange of message meaning to the perceptual or structural shape that encodes the meaning. This shift of attention is in keeping with the meaning of Long and Robinson's focus on form (1998). Not all negotiation involves such a focus on form, however. For example, one interlocutor might fail to interpret the meaning another interlocutor intended due to differences in message content expectations or culturally-grounded world views. Such misinterpretation might lead to a negotiation of message meaning, even 
though the linguistic form of the message is acceptable, appropriate, and not the focus of the conversational repair.

In previous research, instances of form-focused intervention have included interlocutor recasts of learner utterances, as well as models, feedback, and other attention-focusing devices that reveal to learners differences between their own interlanguage and the requirements of their L2 target (Long, 1996). Example 2 illustrates instances of a recast (2a) and implicit corrective feedback (2b).

Example 2:

English L2 Learner

(2a) the boys arrive at station

(Trigger)

(2b) the boys arrive at station

(Trigger)

\section{NS English}

the boys arrived at the station

(Recast)

arrive? do you mean arrived?

(Corrective Feedback)

The recast preserved the lexical items of the learner's utterance, but inserted the before the noun station, and modified the verb with an appropriate ending. Although Example 2a was more targeted than the negotiation signal in Example 1a in drawing the learner's attention to the interlocutor's difficulty with understanding message meaning, neither of these utterances provided optimal linguistic data to the learner. The inexactness of a negotiation signal such as 1a, has been discussed above. Recasts such as 2a have been shown to be effective vehicles for negative evidence in experimental contexts (Long, Inagaki, \& Ortega, 1996), including those that are carried out in experimental content-based classrooms (Doughty \& Varela, 1998). However, they pose potential ambiguity to learners in classrooms that emphasize communication of content and the exchange of message meaning. As Lyster (1998) has shown, recasts are similar in form 
and occurrence to teachers' follow up utterances intended to express acceptance and approval of the students' responses to their questions. Often, students have no obvious way to distinguish the function of a recast based on its form.

\section{Form-Focused Instruction}

Form-focused instruction has been defined as transmission of information about language code and use of corrective feedback within the context of communicative activities (Lightbown \& Spada, 1993, 1999; White, Lightbown, Spada, \& Ranta, 1991). Interactional features can include teacher use of display or evaluation questions, metalinguistic statements, and explicit corrective feedback. Example 3 highlights some of these instructional features, as the NS response utterances provide relevant information about English verbs, as well as corrective feedback on what the learner should do to produce them more accurately.

Example 3:

English L2 Learner

(3a) the boys arrive at station

(Response to Question)

(3b) they at station last week

(Response to Question)
NS English

What happened to the boys? Where did they first arrive?

(Display Questions)

I think you mean arrived because this happened last week. You have to add the ed ending to show past time.

(Metalinguistic Statements)

Yes, I understand what you're saying, but to be correct, you should say arrived not arrive. 


\section{(Explicit Corrective Feedback)}

In form-focused instruction, whether immediate or delayed, there is usually a reference to problems with form, especially the ways in which such problems can interfere with the communication of meaning. There is no immediate communication problem, as there is during negotiation, but interlocutors can refer to problems with meaning and form as a preface to, or within, the implementation of form-focused instruction.

\section{Summary}

This section has summarized similarities and distinctions among negotiation of meaning, form-focused intervention, and form-focused instruction with respect to their interactional features and theoretical roles in assisting the input, feedback, and production needs of L2 learners. Does classroom use of subject-matter content promote these kinds of interaction? Do these interactions draw learners' attention to difficult forms and structures that encode content meaning? These general questions were the basis for the following research questions and study of the interaction in six content-focused L2 classrooms.

\section{RESEARCH QUESTIONS}

1. To what extent do learners and their teachers modify their interaction through negotiation of meaning, form-focused intervention, and form-focused instruction as they participate in activities involving subject-matter content

2. If such modified interaction is found to occur, to what extent does it provide the kinds of input, feedback, and production of modified output that draw attention to developmentally difficult relationships of L2 form and meaning? 
The methodology of the study is described next, together with operational definitions and examples of the variables that were under investigation. METHOD

\section{Content and Activities}

Data for the study came from two advanced level, content-based classes in a university-based English language institute, which comprised numerous programs in academic English, English in business, law, and medical fields, and conversational English. Both content-based classes emphasized cultural, thematic content over linguistic form. One class focused on literature and culture, with students reading and responding to authentic American English literary texts. The other class focused on film and American culture, using videotapes of recent movies, along with reviews and summaries of the movies as its content. The classes were two of a wide range of electives available to students at the institute.

Each class followed a detailed curriculum guide designed by the language institute directors and instructors, two of whom also participated in the study, and other members of the institute staff. Both the literature and film curricula covered a broad variety of interactional activities and formats, consisting of teacher-led and student-tostudent debate and discussion, dialogue journals, at home projects and papers, and inclass presentations. Classes met daily, for 1 hour, over the course of a 7 week session.

\section{Participants}

Participants were two highly experienced, English as a Second Language (ESL) female instructors and their classes of 10-15 high intermediate ESL students. The teachers held advanced degrees in applied linguistics and had over a decade of teaching experience in L2 and FL settings. Each teacher had played a key role in the design of the 
courses under study and had already taught the courses several times. The teacher of the literature course had originated the course, grounding it in principles of whole language and communicative language pedagogy, and was herself carrying out research on student empowerment in her classroom over a series of 7-week sessions, including the session of the present study. The teacher of the film course had been closely involved with course development, with the institute curriculum as a whole, and was coordinator of the intensive English program at the institute. Both teachers believed strongly in the integral connection between language and culture, and thus regarded culture learning as a major contributor to L2 learning.

Students in the literature class came from a wide range of Asian and European L1 backgrounds and ethnicities. Students in the film class were predominantly of Asian L1 backgrounds and ethnicities. Students with Asian backgrounds came primarily from Korea, Taiwan, and Japan. The European students came from Eastern and Western Europe. All were adults who presented academic backgrounds and goals and held at least a bachelor's degree. Most were engaged in full-time English language study and were planning to remain in the United States for further education once they completed their English language studies.

Results of placement and proficiency tests, including the Michigan and TOEFL tests and proficiency interviews, as well as reports and observations of teachers and program administrators, revealed an overall level of communicative proficiency for students, that was consistent with their placements in their respective classrooms. Despite their overall level of communicative proficiency, however, the students also revealed imprecisions and inconsistencies of form in their spoken and written expression of meaning in areas such as making reference to places, people, and events, sequencing 
activities, conditions, and events, as well as foregrounding and backgrounding information, and asserting claims and opinions.

These difficulties with form in the encoding of reference, sequence, modality, and information structure were characterized by underuse or overuse of articles, inappropriate verb tense and aspect marking, and modal verb misselection. As was noted above with respect to Long (1996, such developmentally lingering imprecisions are not unusual in the encoding of form and meaning in areas of low salience such as these.

\section{Data Collection}

Several procedures were followed in the precollection, collection, coding, and analysis of the data for the study. Classes that followed the film and literature curriculum taught by the teachers who were to participate in the study were observed by the researcher and a team of graduate student researchers throughout two 7-week sessions prior to the actual data collection in order to identify comparable interactional activities that could be studied across classes and to determine whether or not there were interactional contexts for expression and understanding of reference, sequence, modality, and information structure.

This period of observation led to the following results: With respect to identification of comparable activities to study, teacher-directed discussion of prior viewings of film or reading of texts was found to be the dominant interactional activity throughout the observation period. Each discussion followed a consistent pattern: It was characterized by utterances that began with frames such as, "I'd like to talk about" or "Let's go on to." These frames served as the initial boundary of the discussion. The final boundary was marked either by the end of the class meeting or a teacher utterance such 
as, “ok, let’s move on to.” Duration of each discussion varied from half to three-fourths of each one hour class meeting time, because other portions of class time were used for classroom management and periodic text rereading or film reviewing in order to support opinions and answers.

Classroom observation also confirmed an abundance of contexts that required the, $a$, and zero articles, as teachers and students referred to characters, places, and events in the films or stories, as well as in reviews, critiques, and summaries. There were also numerous contexts were also found that required inflectional and functor morpheme marking of lexical and modal verbs for time, aspect, and modality in relating story lines, expressing experiences and opinions, advancing arguments, and making speculations. These features were also consistent with the nature of course content and the discourse requirements of the discussion activity.

Data were collected through audio and video tapings of class meetings over the 7week duration of each course. Six sustained, teacher-led classroom discussions about the cultural, thematic, or story content of a literary text or film were chosen at random from a sample of more than 30 such activities, each using frames such as, those noted above.

\section{Data Coding}

The data from the discussions were coded and quantified with respect to teacher and student utterances. Random samples of the data were coded by the researcher and three trained coders, each with backgrounds in applied linguistics. Inter item reliability was .98 for utterances, and ranged between .80 and .99 for all other features described below. All teacher and student utterances were further coded for the following interactional and linguistic features. Examples of these features were described, discussed, and illustrated in Examples 1-3, above, and are operationally defined below: 
1. Negotiation signal utterances: questions, statements, commands, and phrases from one interlocutor, which indicated difficulty in following the other's prior, i.e. trigger, utterance, and requested clarification or confirmation of it.

2. Negotiation trigger utterances: utterances of the other interlocutor that immediately preceded or occurred no more than five utterances prior to a signal utterance.

3. Negotiation response utterances: utterances of the trigger producer that immediately followed a negotiation signal.

4. Form-focused intervention utterances: recasts, which simultaneously modified one or more non-target features of an interlocutor's utterances, but preserved utterance meaning and declarative intonation. Recasts produced with rising intonation and clarification or confirmation request functions, were coded as negotiation signals.

5. Form-focused instruction utterances: questions that asked students to display information known already to their questioner, metalinguistic statements, statements, and phrases of correction and rejection, and lesson-related statements and questions of elicitation and evaluation.

6. Topic switch and topic continuation utterances: utterances that introduced, or switched to, new discussion topics or continued and sustained current topics.

Coding of form-meaning relationships focused on identification of contexts for the following:

1. References to characters, places, and events in film and literary content or reactions thereto that required the, $a$, and zero articles. 
2. Inflectional and functor morpheme marking of lexical and modal verbs for time, aspect, and modality in relating story lines, expressing experiences and opinions, making speculations, advancing arguments, and supporting opinions.

Also noted were whether form-meaning encodings in such contexts were targetlike in their grammatical features, i.e., were consistent with the standard variety of English that was the target of the students’ L2 studies. This procedure was carried out in order to determine whether an utterance of negotiation or form-focused intervention or instruction conveyed positive or negative evidence. The distinction in shown in Example 4. In 4a, which displays positive L2 evidence, the interlocutor extracted the already target-like a movie from the learner's utterance, and continued to use it in a target-like way. In 4b, which shows the provision of negative evidence, the interlocutor offered target versions of the learner's non-target production of the past form of watch.

Example 4:

English Language Learner

NS English

(4a Illustration of Positive L2 Evidence

I watch a movie last week

a movie?

(Negotiation Signal)

a movie last week

(Recast)

Can you think of other ways you can refer to a movie? Think of the review you read. It used a different term. (Form-Focused Instruction)

(4b) Illustration of Negative Evidence: 
I watch a movie last week you watched?

(Negotiation Signal)

you watched a movie last week

(Recast)

Can you think of another way to say watch when you watch a movie in the past? Can you add an ending like -ed?

(Form-Focused Instruction)

\section{RESULTS}

In answer to Research Question 1, the data revealed a low amount of interaction modified by negotiation and negligible amounts of interaction involving form-focused intervention or instruction. With respect to Question 2, the data revealed input, feedback, and learner modified output that contained relatively large amounts of positive L2 evidence and low amounts of negative evidence on the relationships of L2 form and meaning under study. One of the most striking findings of the study was that the majority of student non-target utterances went unaddressed in any direct way. These findings are discussed in more detail below in relation to the research questions of the study.

\section{Results on Question 1}

Question 1 asked whether learners and their teachers engaged in negotiation of meaning, form-focused intervention, and form-focused instruction as they participated in discussions involving subject-matter content. The classroom data revealed that only a small portion of discussion discourse was characterized by these forms of interaction. Table 1 displays the frequencies and proportions of negotiation signal and response 
utterances, form-focused intervention recasts, and form-focused instruction utterances that were found.

\section{$<$ INSERT TABLE 1 HERE $>$}

As shown in Table 1, there were only 358 negotiation utterances from teachers and students out of a total of 4008 utterances. This small figure, which constituted 9\%(1) of the total utterances, represented most of the interaction under investigation, given that there were 17 recasts, 25 utterances of code transmission, and 5 utterances of code correction. Together, these three types of utterances constituted only $1 \%$ of the total utterances of modified interaction of the teachers and students during their discussions.

Although at 9\%, the proportion of negotiation utterances was considerably higher than that of the utterances of form-focused intervention or instruction, this figure was still quite low relative to that found for negotiation in situations involving learners and other nonnative speakers with NSs outside the classroom (Long, 1985), and no better than that found in communicative classroom discussions (Pica \& Doughty, 1985a, 1985b; Pica \& Long, 1986). However, as was argued by Pica, Kanagy, and Falodun (1993), on the basis of findings from these, and similar studies whose data came from discussion, opinion sharing, and other tasks that allowed for divergent views and outcomes, the low incidence of negotiation in the present data may have been more related to the open-endedness of the discussion activity, rather than to the subject-matter content under discussion. Closedended, problem-solving, and information gap tasks might have required greater comprehensibility and accuracy of subject content than the film or literature discussions, and might, therefore, have generated more negotiation on the students' part.

What had been revealed, however, in earlier observation of film and literature classroom interaction, as well as that carried out during the present study, was a relative 
absence of such tasks. Given the high level of students' interest in cinematic and literary content and their teachers' belief in the connections between language learning and culture learning, the discussion seemed to be an inevitable choice as a prominent, highly interactive activity that could engage the students' views. That there was indeed a considerable amount of unmodified interaction around subject content is evident from the near equal distribution of teacher and student utterances during the discussions. As displayed in Table 1, there were 2142 teacher utterances and 1866 student utterances. As such, these utterances constituted 53\% and $47 \%$ of the total of 4008 utterances gathered during the six discussions. However, these utterances seldom required adjustments to be understood. As shown in Excerpt 12, and to be discussed below, classroom discussions moved smoothly, as students communicated message meaning, with little apparent need to attend to the form used to encode it.

Of additional note was the finding that negotiation and form-focused intervention and instruction were largely teacher-provided. Recasts and code transmission and correction utterances were barely evident in the student data. With respect to negotiation, the students' contributions were mainly responses to their teachers, with nearly twice as many student responses (117) to signal utterances (66). Additionally, as will be shown in the excerpts below, many of the students' responses were simple acknowledgments of yes or denials of no, and therefore were not the kind of responses needed to "push" students toward greater syntactic processing of their messages (Swain, 1985).

Observation of the classes as a whole indicated that much of the code transmission and correction the students received was not integrated into class discussions. Instead, the teachers provided lessons on specific structural rules and lexical meanings, in response to students' imprecisions on their written homework assignments 
or contributions in prior classes. Statements and explanations of rules were also provided when students asked questions about grammar in their journal entries. Such attention to L2 form lent further support to the possibility that it was the discussion activity specifically, rather than the subject-matter content in general, that was responsible the low amount of form-focused instruction found in the data.

Also shown in Table 1,199 utterances were provided as signals of message incomprehensibility. These constituted $6 \%$ of teacher and $3 \%$ percent of student utterances. These signals contained most of the negative evidence available during discussion. Given the inexactness of negotiation signals in drawing learners' attention to specific areas of difference between a target L2 version and their own production, these results suggest that the availability of negative evidence during discussion was minimal, and was primarily teacher-supplied.

Students provided few signals to teachers or to each other. As speculated elsewhere (Pica 1987), their lack of signaling suggested either that they comprehended messages with ease, or that they desired to refrain from indicating incomprehension and thereby adhere to classroom norms for deference. This minimization of signals, in turn, resulted in few teacher responses available to students as vehicles of positive L2 evidence. The 117 utterances of student response shown in Table 1 suggest that the teacher and student signals were potentially effective in generating contexts for student production of modified output. However, this possibility was somewhat mitigated by further analysis of the student response data, which revealed mainly repetition of already target-like segments of prior utterances or brief answers of yes or no. (2)

Taken together, results of data analysis with respect to Question 1 revealed a paucity of the kinds of interaction considered helpful to learners' input, feedback, and 
production needs, and a lack of suppliance with respect to the L2 evidence such interactions are known to generate. However, the question remained as to whether or not the evidence, infrequent as it was, was nevertheless targeted toward the form-meaning relationships that were so crucial to the L2 development of the learners in the study. This was what Question 2 aimed to answer. As such, Question 2 focused on the extent to which the input, feedback, and modified production generated by negotiation and formfocused intervention and instruction provided positive and negative evidence of developmentally difficult and complex relationships of L2 form and meaning the students could produce, but had yet to master. Results of data analysis for this question are discussed next.

Results on Question 2

For the form-meaning relationships under study, the data for Question 2 revealed input, feedback, and student production of modified output that contained both positive and negative evidence on L2 form as it was used to encode message meaning, Positive L2 evidence was found in negotiation signals or responses, form-focused recasts, or formfocused instruction utterances that relocated, added, deleted, or substituted a noun article, a verb tense, an aspect morpheme or a modal verb that had been used in a different, but target-like, manner to express a prior utterance. Negative evidence was found when these modifications occurred in a non-target form in a prior utterance. This distinction was illustrated in Example 4.

\section{$<$ INSERT TABLE 2 HERE >}

As shown in Table 2, during negotiation, there were 55 utterances with noun article modifications and 27 with verb tense and aspect modifications, 7 utterances with modal verb modifications, and 5 utterances with some combination thereof. Together, 
these 94 utterances constituted over $54 \%$ of the positive and negative evidence that was available to students during negotiation. Thus, although there were not many utterances of negotiation during the discussion activities of these classrooms, a good portion of their modification involved crucial form-meaning relationships the students needed to acquire.

This aspect of negotiation is shown in Excerpt 1, which, along with Excerpts 214, below, were taken from the actual data of the study. In Excerpt 1, the teacher requested clarification of the student's message regarding his reaction to the film Dim Sum. In so doing, the teacher incorporated the student's target production of speaking and provided positive L2 evidence of verb aspect morphology. The teacher also recast the student's non-target verb inflections of are through substitution of the more time appropriate were. This modification offered negative evidence regarding differences between the student's production and a target version for marking time.

\section{Excerpt 1}

Teacher

what is your basic reaction to Dim Sum?

good! OK
Student

Actually I didn’t understand because when they are speaking Cantonese there are not captions there so they can’t understand it

(Trigger)

when they were speaking Cantonese there were no captions? no

(Negotiation Signal) (Response to Negotiation Signal)

(Film Class) 
As can also be seen in Table 2, however, 87 of the 94 signal and response utterances involved modification of students’ already target-like production. Such exchanges were in keeping with the message-oriented purpose of negotiation. However, the evidence provided with respect to L2 form was largely positive, serving to reinforce students’ already target-like productions. Typically, the teacher would signal incomprehension of the student's preceding utterance, but in so doing, simply extract from it a target-like noun or verb phrase. The non-target form within the student's preceding utterance was often omitted from this signaling feature or follow-up move.

This pattern can be seen in the following exchanges from the data. In Excerpt 2, the teacher's signal substituted the student's possessive pronoun her with the noun article $a$, and in so doing, modified the student's already target-like utterance. In 3, the teacher's response to the student's signal confirmed the form of the student's three uses of the article the in the meaning of the name of the movie? albeit in the context of a slightly different version of the student's utterance.

In Excerpt 4, the teacher’s signal repeated the student’s already target-like expression of form and meaning. The student's utterance, the thing is too slow, was target-like in form, with respect to use of the, but apparently incomprehensible with respect to message meaning. This situation seemed to warrant a more general, message focused confirmation check.

Excerpt 2:

Teacher Student her shadow (Trigger) like $a$ shadow? yeah 
(Negotiation Signal

Mmhm

Topic Continuation Utterance

(Literature class)

Excerpt 3:

Teacher

...so the idea of standing and steady and

testing and producing information or

knowledge is all wrapped up in this title

of this movie--Stand and Deliver

all of these meanings are the meanings

of the name of the movie

(Response to Negotiation Signal

(Film class

\section{Excerpt 4}

Teacher

the theme? these themes?

(Negotiation Signal
(Response to Negotiation Signal)

Student

is that the meaning of the name of the

movie?

(Negotiation Signal
Student

the thing is too slow

(Trigger

no no no no no

(Response to Negotiation Signal 
wh- wha- that's the right meaning but

what's the right word? Anybody know? the

something was too slow

(Negotiation Signal

(Film class

During many negotiated exchanges, the teachers' signals and responses provided only positive evidence when, in fact, negative evidence might have been even more crucial to students' noticing of form and meaning. This pattern can be seen in Excerpts 57. In Excerpt 5, the teacher's extraction of the noun phrase the knitting confirmed student's target production of article the, but the teacher did not modify other non-target features, such as the student's use of does. In Excerpt 6, the teacher modified the student's verb phrase, missed the last part, by extracting it from a longer utterance. However, she did not modify the non-target watch, and thereby missed the opportunity to add an appropriate time inflection to this form. In Excerpt 7, the teacher confirmed the meaning of the student's message through paraphrase. However, she did not signal regarding the non-target people_does.

\section{Excerpt 5}

Teacher

Student

does my feeling was about the knitting is pitiful or or miserable

(Trigger)

the knitting?

(Negotiation Signal yes,

(Response to Negotiation Signal)

and and in this time he he uh I feel that 


\section{(Topic Continuation)}

(Literature class)

\section{Excerpt 6}

Teacher

did you watch it?

Student

uhhuh

I watch it but I missed the last part

I watch it

(Trigger)

you missed the last part?

yeah

(Negotiation Signal)

(Response to Negotiation Signal)

(Film class)

\section{Excerpt 7}

Teacher

Student

I think the message of the author is that we must try to do what we think its good not what other people does only because they do it. because its not perhaps superficially we will be better but our conscience will not eh, we will not accept it. I don’t know. (Trigger)

so we shouldn't succumb?

yeah

(Negotiation Signal)

(Response to Negotiation Signal)

(Literature class) 
Teacher recasts provided consistent negative evidence. As shown in Table 3, there were 11 teacher recasts on the relationships of form and meaning under study. These constituted $65 \%$ of the recast data, and, as shown in the examples below, were occasionally effective in alerting students to their imprecisions. However, they were not numerous in frequency among other teacher utterances.

\section{$<$ INSERT TABLE 3 HERE $>$}

Recasts appeared both during and outside of negotiation. A negotiation recast was illustrated in Excerpt 1, above, as the teacher requested clarification of the student's message, and in so doing modified the student's non-target verb inflections of are through substitution of the more accurate were. Excerpts 8-9 are illustrative of the teachers' recast utterances through their comments and responses, as they recast "go back China," "grow up their children,” and "make them educated” in the students’ speech,.

\section{Excerpt 8}

Teacher

Student

There's another conflict in the mother.

something else is- the mother is thinking a

lot about

go back China

going back to China is one thing

(Recast)

(Film Class)

\section{Excerpt 9}

Teacher

Student 
what do you think uh what do you think uh what can be the best way for parents to grow up their children?

raise their children

(Recast)

the best way to educate them (Rephrasing) what can parents do to make them educated or successful?

(Response to Recast) (Response to Rephrasing)

As with the signals and responses of negotiation, teacher recasts of student nontarget utterances did not always focus on non-target features. This is shown in Excerpt 10, in which the target-like “mustn’t show his humiliation” of a student's prior utterance is recast into new utterance. However, non-target “by don’t give money” is not. Excerpt 10

Teacher

Student yeah if he's still proud he mustn't show his humiliation by don’t give money

right it's humiliation that would show

(Recast)

With respect to student production of modified output, results were similar to those of teacher utterances, with re-incorporation of target-like segments of their original utterances. This reincorporation is shown in Table 4. As with the teacher utterances, there were more student utterances with noun article modification than verb morpheme modification, and hardly any modal or combined modification, for a distribution of 41 , 21, 2, and 5 modified utterances respectively. 


\section{$<$ INSERT TABLE 4 HERE $>$}

.Student-to-student negotiation, though limited in amount, nevertheless, revealed patterns of modification not unlike those of teacher-student interaction. This can be seen in the student-to-student negotiated exchange of Excerpt 11, in which a student modified after to pull don't wear the clothes, but it happen.

Excerpt 11

Student

Student and oh after to pull don't wear the clothes but it happen

(Trigger)

so what

What?

(Negotiation Signal)?

(Negotiation Signal)

after what?

(Negotiation Signal)

take your clothes off after you are finished wearing denim...

(Response to Negotiation Signal)

Another typical outcome was for students to simply acknowledge the teachers' signals with variations of yes or no. This acknowledgment was illustrated in Excerpts 1-2 and 5-7, above. As shown, teachers' signals substituted more target-like forms, while retaining lexical items in the students' original utterances. In so doing, the teachers restricted the students' need to recode their original utterances further, or to draw on their limited interlanguage resources to enhance or modify their contributions in further ways (Pica et al. 1989). 
Finally, not only were very few code transmission and correction utterances found in the corpus of discussion data, there were few among these that addressed the L 2 form and meaning relationships under study. Only one code transmission and three code correction utterances drew students' attention to these features. It is interesting to note, however, that 25 utterances provided form-focused instruction on content-related lexical items.

\section{OTHER FINDINGS}

A notable feature of the discussion interaction was that most of the student utterances with non-target production of the form-meaning relationships under study were not given a direct response of positive or negative evidence. Instead they were followed by utterances of topic continuation or topic switch. This pattern was especially evident when student utterances were embedded in lengthy, but generally comprehensible, texts that the teacher and peer interlocutors did not interrupt with utterances of negotiation, recast through form-focused intervention, or address through form-focused instruction. Instead, they actually prolonged the non-target discourse through back channel utterances and topic sustaining moves.

Thus, as shown in Table 5, 170 of students’ non-target utterances with contexts for noun, verb, and modal suppliance were followed by teacher utterances of topic switch or continuation. They constituted 9\% of the students' total utterances. As also shown, less than $1 \%$ of the students' utterances with these features were followed by responses that carried negative evidence through negotiation or recasting. Many of the students' non-target utterances appeared in long texts without any teacher intervention at all. 
Excerpts 12 and 13 illustrate these phenomena in both teacher-to-student and teacher-to-student and student-to-student interaction during discussion. The underlined phrases reveal the unaddressed, non-target productions. In Excerpt 12, the teacher acknowledged the student's contributions through back channeling, and followed them up with an expression of her own opinion. At the same time, however, the student uttered numerous non-target forms, especially with respect to verbs used to relate the story line, without receiving any intervention at all.

Excerpt 12:

Teacher Student

the daughter have a pretty good but she also hope to get married but she think about her mother. so they are worried each other you know so they pretend they think

mm-hmm they really have a good life at that time mm--hmm but when the her mother go to China back and her mother change change his un thinking and being and then uh her daughter think that then she can get married and her mother can independ on others

really? I had a very different point of view.

(Film Class)

These patterns of back channeling and non-intervention can also be seen in the studentto-student discourse in Excerpt 13.

Excerpt 13: 
Student

yes I think so

yes

(Film Class)

CONCLUSION AND IMPLICATIONS

The use of subject-matter content to support classroom L2 learning has been recognized theoretically, empirically, and pedagogically for its contributions to global L2 proficiency and academic skill development across a broad spectrum of learners. However, concerns have lingered among L2 teachers and researchers about the effectiveness of a content focus for development and mastery of L2 features whose limited saliency often requires attention to form. The present study was an attempt to address those concerns through examination of classroom interaction involving subjectmatter content, particularly with respect to its role in providing negotiation of meaning, form-focused intervention, and form-focused instruction. These interactions are known to provide the kinds of input, feedback, and learner production of modified output that draw 
students' attention to form in relation to content meaning. Of additional interest was whether attention was given to noun articles, verb tense and aspect, and modal verbs, as students and teachers in the study referred to characters and incidents, advanced story lines, gave reactions, made speculations, and presented arguments during their classroom interaction. These form-meaning relationships were important, because they were low in saliency, developmentally difficult, and had not yet been mastered by the students.

Overall, results suggested that subject-matter content in the film and literature classrooms provided a meaningful context for students' exposure to the form and meaning relationships they had yet to master. However, the discussion, as the most frequently implemented interactional activity in these classrooms, did not promote the kinds of interaction that could draw attention to these relationships. Instead, it provided a context for the students to sustain lengthy, multi-utterance texts, whose comprehensibility of message meaning provided little basis for negotiation, form-focused intervention, and form-focused instruction.

The discussions were interesting and meaningful with respect to subject-matter content. However, as open-ended communication activities, they drew attention away from students' need for input and feedback that contained negative evidence on crucial form-meaning relationships in their L2 development. The discussions involved teachers and students in using language to discuss content, but did not focus on the L2 form used to encode content meaning, particularly when the students' own production of form was itself not target-like. Although there were only two teachers who participated in the present study, other research has noted similar results for discussion activities (Pica, Kanagy, \& Falodun 1993). Together, these studies suggest that, in order to address 
learners’ L2 needs, content-based teachers need to find additional ways to promote L2 learning through content in the classroom.

In spite of the limitations of the discussion as a classroom practice, first in the context of communicative language classrooms, and now here, with respect to film and literature L2 classes, this activity continues to dominate the discourse in many classrooms. This decision makes sense in light of its attraction to students' interests, as well as its reliability for teachers in their preparation and coverage of subject-matter content. Thus, the discussion activity appears to be efficient in terms of curriculum decisions and classroom conventions. However, as a task for L2 learning, it falls short of meeting conditions that satisfy learners' needs for positive, and particularly, negative evidence, relevant to L2 learning.

Given the popularity and interest generated by the discussion in content-based classrooms, two approaches might be taken to preserve its place, yet modify its application. One approach would guide teachers in modifying their responses to students' multi-utterance contributions in ways that would generate more input, feedback, and production of student output. The other approach would encourage teachers to use the discussion as an initial activity to introduce or review content, and then follow it with interactive, form-focusing tasks that promote opportunities for more targeted input, feedback, and student production of modified output.

In implementing the first approach, teachers' modified responses could include planned intervention strategies that would prompt students to speak at length, and at the same time recast their non-target encodings of form as they advanced message meaning. This approach would be patterned on the work of Doughty and Varela (1998), whose research revealed ways in which teacher recasts of student responses in science 
classrooms were able to advance their development of verb form and meaning. Using this approach text such as that shown in Excerpt 12 might resemble the following, shown here as Excerpt 14):

Excerpt 14:

Teacher

Student

the daughter have a pretty good but she also hope to get married but she think about her mother. so they are worried each other you know so they pretend they think

mm-hmm, yes she hoped to get married, but she thought about her mother

they really have a good life at that time mm--hmm but when the her mother go to China back and her mother change change his un thinking and being and then uh her daughter think that then she can get married and her mother can independ on others

really? The daughter thought that her

mother could depend on others? I had a

very different point of view.

(Film Class)

As the italicized segments show, the teacher's two responses recast the student's use of think into a more target form. In so doing, she preserved the discussion format, but provided implicit negative evidence, and target versions of the student's think. Because teacher recasts would follow utterances that students generated themselves, rather than 
produced in response to teacher display questions, they would be less likely to be confused with the approval function that is characteristic of teacher follow up utterances in lessons (Lyster, 1998).

In addition to inserting recasts to convey implicit negative evidence during discussion activities, teachers could also employ classroom tasks that require precision of form and content, and responses of negative evidence as necessities for their completion. Close-ended information exchange tasks would be especially conducive to this outcome. For example, students might be asked to reconstruct a scene from a film or story by pooling individual story lines in strip story format, which would then need to be placed in order of occurrence. Alternatively, they might be asked to participate in a dictogloss task, taking notes on a passage or scene, then using the notes for collaborative reconstruction it. Research (Swain 1995) has shown as students collaborate on reconstruction tasks they are able to provide each other with negative evidence and use this evidence as a basis for modifying their imprecise production.

In light of these possible directions, additional research is now underway by the researcher and administrators of the present study, along with newly assigned teachers in content classes. Form-focusing tasks in six categories have been developed for the same film curriculum that was used in the present study. These tasks draw on the same scripts, reviews, and summaries that were the basis of discussion activities in the study (Pica et al., 2001). Task categories include "Spot the Difference” (Crookes \& Rulon 1988; Long, 1981), “Dictogloss” (Swain, 1998; Wajnryb, 1990), “Jig-Saw Story Construction” (Pica, Lincoln-Porter, Paninos, \& Linnell, 1996), and several different approaches to the “Grammar Based Communication Task” (Ellis, 1998; Fotos, 1994, Loschky \& BleyVroman, 1993). Preliminary data collection has revealed students actively engaged in 
drawing each others' attention to form as they advance their message meaning, using the very scripts and reviews that had failed to inspire their attention to form during discussion (Pica et al., 2001).

The content-based classroom has much to offer students in their L2 learning experience, but it needs a broader repertoire of activities than the discussion, if it is to serve students’ many needs and goals. Collaborative, form-focused tasks can be easily produced and incorporated into a curriculum organized around subject-matter content. Grounded in theory and research on L2 learning and teaching, these tasks can not only enrich content learning, but also broaden perspectives on the role of content in classroom L2 learning.

\section{Acknowledgments}

Many thanks to the following research assistants and associates who helped with the data collection and analysis: Sharon Bode, Ruth Boyd-Kletzander, Bruce Evans. Daniel Jackson, Victoria Jo, and Jess Unger. Thanks also to my colleagues, Gay Washburn, , Kristine Billmyer, Mara Blake-Ward, Lyn Buchheit, Mary Ann Julian, Sharon Nicolary, Jack Sullivan, and Helen Yung for their feedback and support throughout this, and other related, projects. 
Notes

1. Percentage figures that show $0 \%$ on frequency data have been rounded to the nearest percent.

2. This finding is displayed in Table 4, and will be discussed with the information in Table 4. 


\section{References}

Aston, G. (1986). Trouble-shooting in interaction with learners: the more the merrier? Applied Linguistics, 7, 128-143.

Brinton, D. (2000). Out of the mouths of babes: Novice teacher insights into contentbased instruction. In L. Kasper, M. Babbitt, \& R. Mlynarczyk (Eds.) Content-based college ESL instruction (pp. 48-70). Mahwah, New Jersey: Erlbaum. 
Brinton, D., Snow, M. A., \& Wesche, M. (1989). Content-based second language instruction. New York: Newbury House.

Carson, J., Taylor, J., \& Fredella, L. (1997). The role of content in task-based EAP instruction. In M. A. Snow \& D. Brinton (Eds.) The content-based classroom: Perspectives on integrating language and content (pp. 367-370). White Plains, NY: Longman.

Crookes, G., \& Rulon, K. A. (1988). Topic and feedback in native speaker/non-native speaker conversation. TESOL Quarterly, 22, 675-681.

Doughty, C., \& Varela, E. (1998). Communicative focus on form. In C. Doughty \& J. Williams (Eds.) Focus on form in second language classroom (pp. 114-138). New York: Cambridge University Press.

Doughty, C, \& Williams, J. (Eds.). (1998). Focus on form in second language classroom. New York: Cambridge University Press.

Ellis, R. (1994). The study of second language acquisition. Oxford: Oxford University Press.

Ellis, R. (1998). Teaching and research: options in grammar teaching. TESOL Quarterly, 32, 39-60. 
Foster, P. (1998). A classroom perspective on the negotiation of meaning. Applied Linguistics 9, 1-23.

Fotos, S. (1994). Integrating grammar instruction and communicative language use through grammar consciousness-raising tasks. TESOL Quarterly, 28, 323-351.

Freeman, D., Freeman, Y., \& Gonzalez, R. (1987). Success for LEPs: The sunnyside sheltered English program. TESOL Quarterly, 21, 361-367.

Gass, S., \& Selinker, L. (1994). Second language acquisition: An introductory course. Hillsdale, NJ: Lawrence Erlbaum.

Genesee, F., Polich, E., \& Stanley, M. (1977). An experimental French immersion program at the secondary school level 1969 to 1974. Canadian Modern Language Review, 33, 318-332.

Giauque, G. (1987). Teaching for content in a skills course: Greek mythology in French. Foreign Language Annals, 20, 565-569.

Graham, J. G., \& Beardsley, R. S. (1986). English for specific purposes: Content, language, and communication in a pharmacy course model. TESOL Quarterly, 20, 227245. 
Harley, B. (1989). Functional grammar in French immersion: A classroom experiment. Applied Linguistics, 10, 331-359.

Harley, B. (1993). Instructional strategies and second language acquisition in early French immersion. Studies in Second Language Acquisition, 15, 245-260.

Hart, D., \& Lapkin, S. (1989). French immersion at the secondary/postsecondary interface: Report to the Ontario Ministry of Colleges and Universities. Modern Language Center, Ontario Institute for Studies in Education.

Hauptman, P. C., Wesche, M., \& Ready, D. (1988). Second-language acquisition through subject-matter learning: A follow-up study at the University of Ottawa. Language Learning, 38, 433-461.

Ho, K. K. (1982). Effect of language of instruction on physics achievement. Journal of Research in Science Teaching, 19, 761-767.

Hudson, T. (1991). A content comprehension approach to reading English for Science and technology. TESOL Quarterly, 25, 77-104.

Lafayette, R., \& Buscaglia, M. (1985). Students learn language via a civilization course: A comparison of second language classroom environments. Studies in Second Language Acquisition, 7, 323-342. 
Leaver, B. L., \& Stryker, S. B. (1989). Content-based instruction for foreign language classroom. Foreign Language Annals, 22, 269-275.

Lightbown, P., \& Spada, N. (1993). How languages are learned. Oxford: Oxford University Press.

Lightbown, P., \& Spada, N. (1999). How languages are learned (Rev. Ed.) Oxford: Oxford University Press.

Linnell, J. (1995). Negotiation as an aid to syntacticization. Unpublished doctoral dissertation, University of Pennsylvania.

Long, M. (1981). Input, interaction, and second language acquisition. In H. Winitz (Ed.), Native language and foreign language acquisition (pp. 259-278). Annals of the New York Academy of Sciences, Vol. 379.

Long, M. (1985). Input and second language acquisition theory. In S. Gass, \& C. Madden (Eds.), Input in second language acquisition (pp. 377-393). Rowley, MA: Newbury House.

Long, M. (1996). The role of the linguistic environment in second language acquisition.

In W. C. Ritchie \& T. K. Bhatia (Eds.), Handbook of language acquisition: Vol. 2. Second language acquisition (pp. 413-468). New York: Academic Press. 
Long, M., Inagaki, S, \& Ortega, L. (1998). The role of implicit negative evidence in SLA: Models and recasts in Japanese and Spanish. Modern Language Journal, 82, 357371.

Long, M., \& Robinson, P. (1998). Focus on form: Theory, research, and practice. In C. Doughty \& J. Williams (Eds.), Focus on form in second language classroom (pp. 15-41). New York: Cambridge University Press.

Loschky, L., \& Bley-Vroman, R. (1993). Creating structure-based communication tasks for second language development. In G. Crookes \& S. Gass (Eds.). Tasks and language learning: integrating theory and practice (pp. 123-167). Clevedon, England: Multilingual Matters.

Lyster, R. (1998). Recasts, repetition, and ambiguity in L2 classroom discourse. Studies in Second Language Acquisition, 20, 51-82.

Mohan, B. A. (1979). Relating language teaching and content teaching. TESOL Quarterly, 13, 171-182.

Peck, S. (1987). Spanish for social workers: An intermediate level communicative course with content lectures. Modern Language Journal, 71, 402-409.

Pica, T. (1987). Second language acquisition, social interaction, and the classroom. Applied Linguistics 8, 3-21. 
Pica, T. (1992). The textual outcomes of native speaker-non-native speaker negotiation. In C. Kramsch \& S. McConnell-Ginet (Eds.), Text and context: Cross-disciplinary perspectives on language study (pp. 198-237). Lexington, MA: Heath.

Pica, T. (1994). Research on negotiation: What does it reveal about second language learning conditions, processes, and outcomes? Language Learning, 44, 493-527.

Pica, T. (1997, October). Focus on form in content based second language classrooms. Paper presented at Annual Second Language Research Forum, East Lansing, MI.

Pica, T., Billmyer, K., Julian, M., Blake-Ward, M., Buchheit, L., Nicolary, S., \& Sullivan, J. (2001, February 24). From content-based texts to form-focused tasks: An integration of second language theory, research, and pedagogy. Paper presented at Annual AAAL Conference, St. Louis, MO..

Pica, T., \& Doughty, C. (1985a). Input and interaction in the communicative language classroom: A comparison of teacher-fronted and group activities. In S. Gass \& C. Madden (Eds.), Input in second language acquisition (pp. 115-132). Rowley, MA: Newbury House.

Pica, T., \& Doughty, C. (1985b). The role of group work in classroom second language acquisition. Studies in Second Language Acquisition, 7, 233-248. 
Pica, T., Holliday, L., Lewis, N., \& Morgenthaler, L. (1989). Comprehensible output as an outcome of linguistic demands on the learner. Studies in Second Language Acquisition, 11, 63-90.

Pica, T., Holliday, L., Lewis, N., Berducci, D., \& Newman, J. (1991). Language learning through interaction: What role does gender play? Studies in Second Language Acquisition, 13, 343-76.

Pica, T., Kanagy, R., \& Falodun, J. (1993). Choosing and using communication tasks for second language instruction. In G. Crookes \& S. Gass (Eds.), Tasks and language learning (pp. 9-34). Clevedon, England: Multilingual Matters.

Pica, T., Lincoln-Porter, F., Paninos, D., \& Linnell, J. (1996). Language learners’ interaction: How does it address the input, output, and feedback needs of L2 learners? TESOL Quarterly, 30, 59-84.

Pica, T., \& Long, M. (1986). The linguistic and conversational performance of experienced and inexperienced teachers. In R. Day (Ed.), Talking to learn: Conversation in second language acquisition (pp. 85-98). Rowley, MA: Newbury House.

Pica, T., Washburn, G, Evans, B., \& Jo, V. (1998, January). Negative feedback in content-based second language classroom interaction: How does it contribute to second language learning? Annual Pacific Second Language Research Forum, Tokyo, Japan. 
Sato, C. (1986). Conversation and interlanguage development: Rethinking the connection. In R. Day (Ed.). Talking to learn: Conversation in second language acquisition. (pp. 5-22), Rowley, MA: Newbury House.

Snow, M.A., \& Brinton, D. M. (1988). Content-based language instruction: Investigating the effectiveness of the adjunct model. TESOL Quarterly, 22, 553-574.

Snow, M. A., \& Brinton, D. M. (1997). The Content-based Classroom: Perspectives on integrating language and content. New York: Addison Wesley Longman.

Spilka, I. (1976). Assessment of second-language performance in immersion program. Canadian Modern Language Review, 32, 543-561.

Sternfeld, S. (1988). The applicability of the immersion approach to college foreign language instruction. Foreign Language Annals, 21, 221-226.

Sternfeld, S. (1989). The University of Utah's Immersion/Multiliteracy Program: An example of an area studies approach to the design of first-year college foreign language instruction. Foreign Language_Annals, 22, 341-352.

Stoller, F. \& Grabbe, W. (1997) A six-t’s approach to content-based instruction. In M. Snow \& M. D. Brinton Eds.), The Content-based classroom: Perspectives on integrating language and content (pp. 78-84). New York: Addison Wesley Longman. 
Swain, M. (1985). Communicative competence: Some roles of comprehensible input and comprehensible output in its development. In S. Gass \& C. Madden (Eds.), Input in second language acquisition (pp. 235-253). Rowley, MA: Newbury House.

Swain, M. (1988). Manipulating and complementing content teaching to maximize second language learning. TESL Canada Journal, 6, 68-83.

Swain, M. (1991). French immersion and its offshoots: Getting two for one. In B. Freed (Ed.), Foreign language acquisition and the classroom (pp. 91-103). Lexington, MA: Heath.

Swain, M. (1995). Three functions of output in second language learning. In G. Cook \& B. Seidlhofer (Eds.), For H. G. Widdowson: Principles and practice in the study of language. (pp. 125-144). Oxford: Oxford University Press.

Swain, M. (1996). Discovering successful second language teaching strategies and practices: From program evaluation to classroom experimentation. Journal of Multilingual and Multicultural Development 17, 89-104.

Swain, M. (1998). Focus on form through conscious reflection. In C. Doughty \& J. Williams (Eds.), Focus on form in classroom second language acquisition. (pp. 64-82). New York: Cambridge University Press. 
Swain, M. \& Carroll, S. (1987). The immersion observation study. in B. Harley, P. Allen, J. Cummins, \& M. Swain (Eds.), The development of bilingual proficiency. Final Report. Vol. II (pp. 190-263). Toronto: The Institute for Studies in Education.

Swain, M. \& Lapkin, S. (1989). Canadian immersion and adult second language teaching: What's the connection? Modern Language Journal, 73, 150-159.

Wajnryb, R. (1990). Grammar Dictation. Oxford: Oxford University Press.

Wesche, M. (1985). Immersion and the universities. The Canadian Modern Language Review, 41, 931-940.

Wesche, M. (1992). French immersion graduates at university and beyond: What difference has it made? In J. Alatis (Ed.), Georgetown University Round Table on Languages and Linguistics 1992: Language, communication, and social meaning (pp. 208-240). Washington, DC: Georgetown University Press.

White, L., Spada, N., Lightbown, P., Ranta, L. (1991). Input enhancement and L2 question formation. Applied Linguistics, 12, 416-432.

Zuengler, J., \& Brinton, D. (1997). Linguistic form, pragmatic function: Relevant research from content-based instruction. In M.A. Snow \& D.M. Brinton, The contentbased classroom: Perspectives on integrating language and content (pp. 268-73). New York: Addison Wesley Longman. 
55 Subject Matter Content 


\section{TABLE 1}

Negotiation, Form-Focused Intervention, Form-Focused Instruction

$n \begin{aligned} & \text { Teachers } \\ & \% \text { Total } \\ & \text { Utterances }\end{aligned}$

Students
$n \quad$ \% Total
Utterances

Totals

Negotiation

$\begin{array}{llll}1 & 3 & 3 & 6 \%\end{array}$

66

$3 \%$

n \% Total

Signal

Utterances

Negotiation

42

$2 \%$

$\begin{array}{lll}1 & 1 & 7\end{array}$

$6 \%$

159

$4 \%$

Response

Utterances

Total

175

$8 \%$

183

$10 \%$

358

$9 \%$

Negotiation

Signal and

Response

Utterances

Form-Focused

17

0\%

0

$0 \%$

17 Utterances

Intervention

Utterances

(Recasts)

Form-Focused

Instruction

Utterances:

Code

24

$1 \%$

1

$0 \%$

25

$1 \%$

Transmission

Code

$$
5
$$

$0 \%$

0

$0 \%$

5

$0 \%$

Correction

Total

$\begin{array}{lllll}2 & 2 & 1 & 1 & 0 \%\end{array}$

184

$10 \%$

405

$10 \%$

Negotiation,

Form-Focused

Intervention, 
and

Instruction

Utterances

Total

$$
2 \quad 142
$$

$\begin{array}{llllll}5 & 3 \% & 1 & 8 & 6 & 6\end{array}$

$47 \%$

$\begin{array}{llll}4 & 0 & 0 & 8\end{array}$

$100 \%$

Utterances

\section{TABLE 2}

Teachers’ Negotiation, with Modification of Students' Target and Non-Target Productions

$$
n \%
$$

Negotiation

Utterances

Teachers' Modification of Students':

Target Noun Articles

Non-Target Noun Articles

Target Verb Tense/Aspect

Non-Target Verb Tense/Aspect

Target Modal Verbs

Non-Target Modal Verbs

Target Noun Articles, and/or Verb

Tense/Aspect and/or Modal Verbs

Non-Target Noun Articles, and/or Verb

Tense/Aspect and/or Modal Verbs

Total Teachers’ Modification

Target

Non-Target

$\begin{array}{rrrrr}5 & 3 & 3 & 0 & \% \\ 2 & & & 1 & \%\end{array}$

$2213 \%$

$5 \quad 3 \%$

$7 \quad 4 \%$

$0 \quad 0 \%$

$5 \quad 3 \%$

$0 \quad 0 \%$

$\begin{array}{lllll}9 & 4 & 5 & 4 & \%\end{array}$

$\begin{array}{lllll}8 & 7 & 5 & 0 & \%\end{array}$

$7 \quad 4 \%$




\section{TABLE 3}

Teachers’ Recasts of Students’ Target and Non-Target Productions

$n$

\% Recast

Utterances

Teachers’ Recasts of Students’ Production of:

Target Noun Articles

Non-Target Noun Articles

Target Verb Tense/Aspect

Non-target Verb Tense/Aspect

Target Modal Verbs

Non-Target Modal Verbs

Target Noun Articles, and/or Verb Tense/Aspect

and/or Modal Verbs

Non-Target Noun Articles, and/or Verb
2

3

0

5

0

0

1

0
$0 \%$

$29 \%$

$1 \%$

$12 \%$

$18 \%$

$0 \%$

$0 \%$

$0 \%$ 
Tense/Aspect Form and/or Modal Verbs

Other Teacher Recasts

$35 \%$

Total Teacher Recasts

17

$1 \quad 0 \quad 0 \%$

TABLE 4

Student Responses of Modified Production

$n$

40

Target Noun Articles

Non-Target Noun Articles

Target Verb Tense/Aspect

Non-Target Verb Tense/Aspect

Target Modal Verbs

Non-Target Modal Verbs
2

0
Students’ Modified Production of:
\% Student

Response

Utterances 
and/or Modal Verbs

Non-Target Noun Articles, and/or Verb

$0 \%$

Tense/Aspect and/or Modal Verb

Total Student Modified Production

$\begin{array}{rrrrrr} & 6 & 9 & & 5 & 9 \% \\ 1 & 1 & 7 & 1 & 0 & 0 \%\end{array}$

Total Student Response Utterances

$\begin{array}{lll}1 & 1 & 7\end{array}$

$1.0 \%$

TABLE 5

Students’ Non-Target Productions and Teachers’ Following Utterances

$\begin{array}{ccc}\text { Teachers' Following } & \text { Teachers' Following } & \text { Teachers' Following } \\ \text { Utterances of Topic } & \text { Utterances of } & \text { Recast Utterances } \\ \text { Switch or } & \text { Negotiation } & \\ \text { Continuation } & & \end{array}$

$\begin{array}{cccccc}n & \% \text { Total } & n & \% \text { Total } & n & \% \text { Total } \\ \text { Student } & & \text { Student } & & \text { Student } \\ & & & & \\ \text { Utterances } & & \text { Utterances } & & \text { Utterances }\end{array}$

Students'

Non- 


\section{Target}

Utterances

with

Contexts

for

Suppliance

of:

Noun

52

$3 \%$

$2 \quad 0 \%$

$3 \quad 0 \%$

Articles

Verb

$\begin{array}{lll}1 & 1 & 7\end{array}$

$6 \%$

5

$0 \%$

$5 \quad 0 \%$

Tense/

Aspect

Modal

1

$0 \%$

0

$0 \%$

0

$0 \%$

Verbs

Total

$\begin{array}{lll}1 & 7 & 0\end{array}$

$9 \%$

7

$0 \%$

$8 \quad 0 \%$ 